\title{
Comparative Winds' Statistical Distributions Study for the Central Southern Region of Brazil
}

Alexandre Ceretta Dalla Favera*[1], Nelson Jorge Schuch [1], Fernando Ramos Martins [2], Marcio Ceconi [1], Eduardo Weide Luiz [1], Enio Bueno Pereira [2] ([1] Southern Regional Space Center - CRS/CCR/INPE-MCT; and [2] Center for Earth System Science/Brazilian Institute for Space Research (CCST/INPE)).

Copyright 2011, SBGf - Sociedade Brasileira de Geofísica

This paper was prepared for presentation during the $12^{\text {th }}$ International Congress of the Brazilian Geophysical Society held in Rio de Janeiro, Brazil, August 15-18, 2011.

Contents of this paper were reviewed by the Technical Committee of the $12^{\text {th }}$ International Congress of the Brazilian Geophysical Society and do not necessarily represent any position of the SBGf, its officers or members. Electronic reproduction or storage of any part of this paper for commercial purposes without the written consent of the Brazilian Geophysical Society is prohibited.

\section{Abstract (Font: Arial Bold, 9)}

The industrial and social development of a country requires large amounts of energy, particularly electricity. To follow the development with an efficient power grid, the human society has sought alternative energy sources that are economically and ecologically viable. The wind energy is one of such alternatives. However, the deployment of wind farms requires a previous study of the winds' statistical profile in the region of interest. With this in mind, this work performs an analysis of three different statistical distributions to see which best fits the wind profile in the Central Region of the South of Brazil. The Weibull, Log Normal and Rayleigh statistical distribution were studied and compared with the values of wind speed collected at 50 meters from the SONDA site operating in São Martinho da Serra, RS in the Southern Space Observatory - OES/CRS/CCR/INPE-MCT. The analysis was performed between 2005 and 2009 showed that among the three distributions, the Weibull presents the best correlation and the smaller errors, MBE and RMSE.

\section{Introduction}

Seldom we realize how essential electricity is to keep the human society living in its current way of life. Most of the time, the awareness arises in periods of energy crisis, as the electricity blackout happened in 2001 in Brazil, known as "Apagão". The electricity shortage was due to low rainfall and consequent low water storage in power plants reservoirs. This shows how much Brazilian electricity matrix is vulnerable to climate variability. Next to that, there is an intense socio-economical growth in the country, requiring large amounts of energy for housing, industrial and commercial activities. Diversifying the electricity matrix and increasing the share for renewable sources such as wind power will improve the reliability of Brazilian electricity system without increasing greenhouse gases emissions.

It has been shown by Amêndola (2007) that the wind energy is considered clean and renewable and do not prejudice or slightly affect the environment and human health, since does not emit toxic gases and particulate materials.
According to Grimm (1999), wind turbines are responsible for transforming the motion energy of the wind into mechanical energy by moving turbine's blades, and subsequent conversion into electric energy. However, to obtain a good benefit-cost ratio of this source it is required to increase knowledge and disseminate reliable information on assessment and variability of the wind power density for a region of interest.

In general, the turbines work according to speed ranges, as shown in Figure 1. The extraction of the air flow by the turbines' blades generates particular amounts of power for each speed.

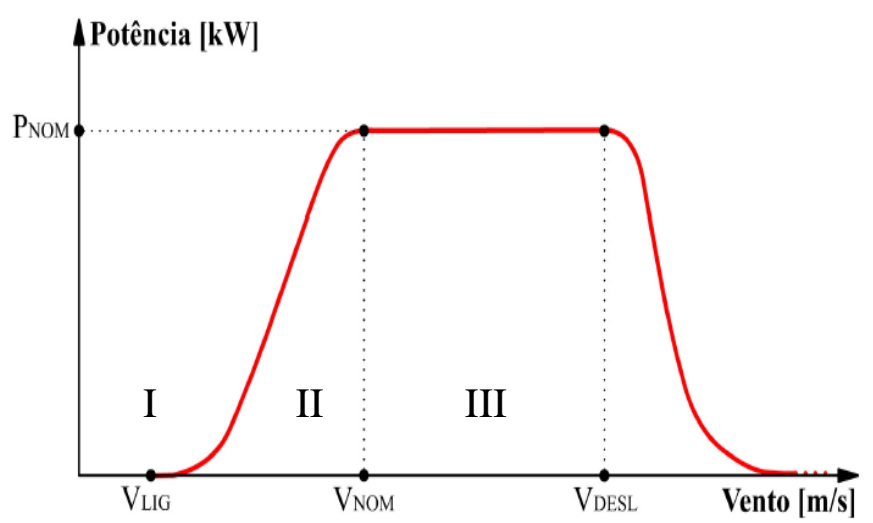

Fig. 1.Wind speed's ranges for the operation of a wind turbine. Source: Amêndola (2007).

As described in Marques (2004), section I of Figure 1 refers the starting point of the wind turbine, i.e. the minimum wind speed operation $\left(\mathrm{V}_{\mathrm{LIG}}\right)$. For most of the commercial turbines it is around 3 to $5 \mathrm{~m} / \mathrm{s}$. Section II refers to the normal operation $\left(\mathrm{V}_{\mathrm{NOM}}\right)$ of the turbine. In this section, wind turbine can operate at constant or variables speeds, depending of the type of turbine. The wind turbine produces the same power for the entire section III, called nominal potential $\left(\mathrm{P}_{\mathrm{NOM}}\right)$ of the turbine, usually at speeds between 12 to $25 \mathrm{~m} / \mathrm{s}$. At greater speeds than $\mathrm{V}_{\mathrm{DESL}}$, the cutting speed. Usually above $25 \mathrm{~m} / \mathrm{s}$, the wind turbine shut down in order to do not damage its structure.

In order to achieve a minimum trustworthiness of the wind power potential of a region, it is necessary a long term database. Usually, the wind presents large time variability, thus it is used statistical process to outline the wind behavior. In cases where are slow variations it's 
commonly used the probability density function to describe the chance that the wind velocity achieve a specific value. According to Castro (2008), the results indicated by the probability densities have great value when they are described analytically.

The study, conducted at the Laboratory of Renewable Energy Resources of the Southern Regional Center for Space Research - LRER/CRS/CCR/INPE-MCT, aims to evaluate which statistical distribution presents the best fit for the wind data acquired in the Southern Space Observatory - OES/CRS/CCR/INPE-MCT in São Martinho da Serra, RS. This SONDA measurement site is located in central area of the Southern region of Brazil.

\section{Method}

The wind's speed and direction data used in the study were acquired from the measurement site of the SONDA network (www.ccst.inpe.br/sonda) located at the Southern Space Observatory in central area of the Brazilian Southern region. The site owns climatological and radiometric sensors and an anemometric tower containing three anemometers at the heights of 10, 25 and 50 meters above ground, as shown in Figure. 2.

The selected database period for the study covers from January 2005 through December 2009 for the height of 50 meters with temporal resolution of 10 minutes of action. The wind data were submitted to a quality control program as described in Chagas et al (2006).

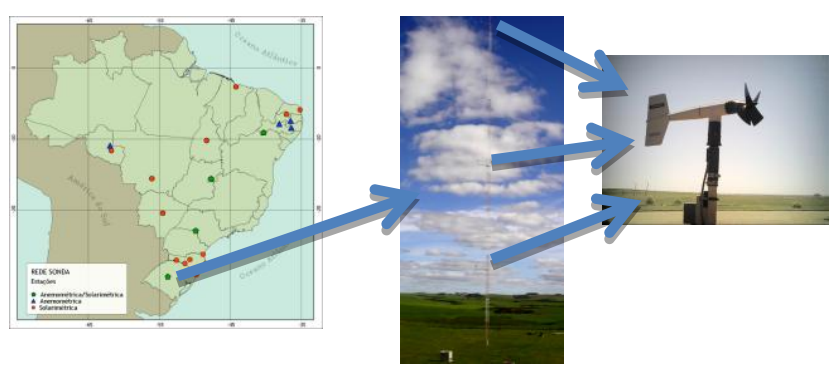

Fig. 2.Anemometric tower operating at the Southern Space Observatory - OES/CRS/CCR/INPE-MCT.

Three different statistical density functions were evaluated: Weibull, Log Normal and Rayleigh.

The Weibull probability density function is described by Equation 1:

$f_{W}(v)=\frac{k}{A}\left(\frac{v}{A}\right)^{k-1} e^{-\left(\frac{v}{A}\right)^{k}}$

where $f_{W}(v)$ is the frequency of occurrence of each horizontal wind speed $\mathrm{v} ; k$ is the shape parameter and $A$ is a scale parameter. The shape $(k)$ and scale $(A)$ parameters were obtained from the WAsP®) (Wind Atlas Analysis and Application Program) software.

The Log-normal probability density function distribution is depicted by Equation 2:

$f_{L G}(v)=\frac{1}{v \sigma \sqrt{2 \pi}} e^{-\frac{(\ln v-\mu)^{2}}{2 \sigma^{2}}}$ where $f_{L G}(v)$ is the frequency of occurrence of each horizontal wind speed $v ; \mu$ is the location parameter and $\sigma$ is a scale parameter. The $\mu$ and $\sigma$ parameters are respectively mean and standard deviation of natural logarithms of $v$. Both parameters can be calculated by:

$\mu=\ln v_{\text {med }}-\frac{1}{2} \ln \left(1+\frac{V A R(v)}{v_{\text {med }^{2}}{ }^{2}}\right)$

$\sigma^{2}=\ln \left(1+\frac{V A R(v)}{v_{m e d}{ }^{2}}\right)$

where $v_{\text {med }}$ is the average speed and $V A R(v)$ is the variance of the wind velocity $v$.

The probability density function of the Rayleigh distribution is provided by Equation 5:

$f_{R}(v)=\frac{\pi}{2} \frac{v}{v_{\text {med }^{2}}} e^{-\left(\frac{\pi}{4}\right)\left(\frac{v}{v_{\text {med }}}\right)^{2}}$

where $f_{R}(v)$ is the frequency of occurrence of each horizontal wind speed $v$; and $v_{\text {med }}$ is the average speed.

In order to check the suitability of the proposed statistical distributions to the data acquired at SONDA site a validation process was performed by calculating the statistical deviations MBE (Mean Bias Error) and RMSE (Root Mean Square Error). Also, the correlation factor between measured data and estimates provided by Weibull, Log Normal and Rayleigh distributions. The MBE deviation indicates the systematic deviation of the estimates, while the RMSE represents a measure of dispersion around the estimated values of measured values.

\section{Results}

The Figures 3 and 4 shows the histogram and wind rose obtained from wind's speed and direction data collected from January 2005 to December 2009 at 50 meters high in the Southern Space Observatory. The histogram represents the wind velocity frequency in columns, and the wind rose outlines the wind direction frequency.

The histogram was constructed with columns' strip width of $1 \mathrm{~m} / \mathrm{s}$, due to be the most often found in the literature (Castro, 2008).

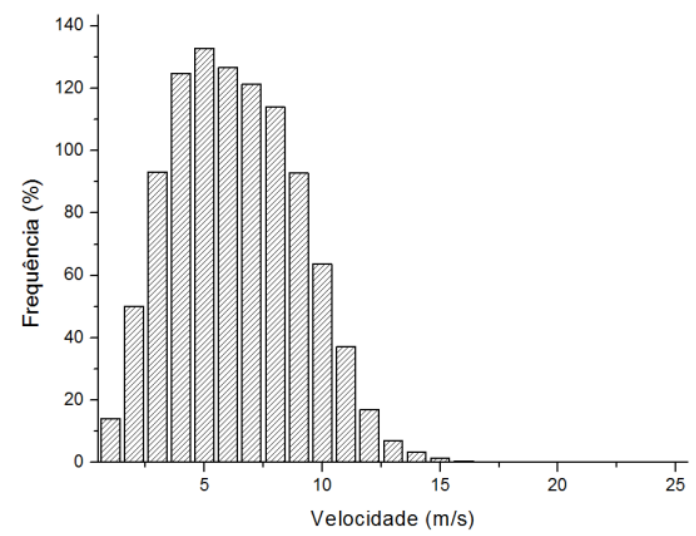

Fig. 3. Histogram for $50 \mathrm{~m}$ high wind velocity data acquired at the São Martinho da Serra, SONDA measurement site in the Southern region of Brazil. 


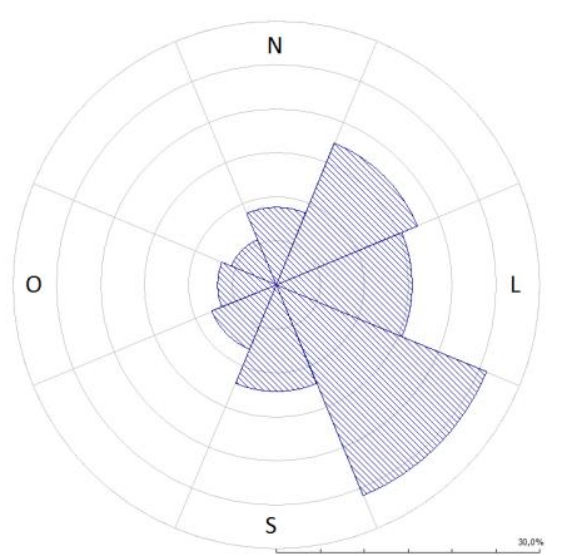

Fig. 4. Wind rose for $50 \mathrm{~m}$ high wind velocity data acquired at the São Martinho da Serra, SONDA measurement site in the Southern region of Brazil.

In the Table 1 presents the descriptive statistics obtained for wind data collected in São Martinho da Serra.

Table 1.Descriptive Statistics for wind data collected at the Southern Space Observatory, São Martinho da Serra, RS.

\begin{tabular}{l|l}
\hline Analyzed Period & January 2005 to December 2009 \\
\hline $\begin{array}{l}\text { Total Number of Data } \\
\text { Temporal resolution of } \\
\text { data collection }\end{array}$ & 270,368 \\
\hline Average speed $(\mathrm{m} / \mathrm{s})$ & 5.64 \\
\hline Median speed $(\mathrm{m} / \mathrm{s})$ & 5.19 \\
\hline Standard Deviation & 3.63 \\
\hline Variance & 13.18 \\
\hline
\end{tabular}

From the wind speed data, it was calculated the shape (k) and scale (A) parameters for the Weibull distribution; position $(\mu)$ and scale $(\sigma)$ parameters for the Log Normal distribution and average speed for the Rayleigh distribution, represented respectively, in equations 8,9 and 10:

$$
\begin{aligned}
& f_{W}(v)=\frac{2,40}{6,60}\left(\frac{v}{6,60}\right)^{2,40-1} e^{-\left(\frac{v}{6,60}\right)^{2,40}} \\
& f_{L G}(v)=\frac{1}{0,59 v \sqrt{2 \pi}} e^{-\frac{(\ln v-1,56)^{2}}{2 \cdot 0,59^{2}}} \\
& f_{R}(v)=\frac{\pi}{2} \frac{v}{5,64^{2}} e^{-\left(\frac{\pi}{4}\right)\left(\frac{v}{5,64^{2}}\right)^{2}}
\end{aligned}
$$

After obtain the frequencies calculated by statistical distributions represented in equations 8,9 and 10 was conducted the validation stage by calculating the statistical deviations RMSE and MBE, shown in Table 2. It can be observed that the Weibull distribution provides the best correlation (96\%) and lowest deviations, both MBE $(0.07 \%)$ and RMSE (25\%). Followed by the Rayleigh distribution and lastly the Log Normal distribution.
The same result can be seen from Figure 5 that shows the relation between the measured and the estimated values. The Weibull distribution is closer to the function $y=x$, which indicates a lower dispersion of the measured data.

Table 2. Statistics distributions validation by calculating the statistical deviations MBE and RMSE.

\begin{tabular}{l|l|l|l|l|l}
\hline \multicolumn{2}{l|}{ Weibull } & \multicolumn{2}{l|}{ Log Normal } & \multicolumn{2}{l}{ Rayleigh } \\
\hline $\mathrm{R}$ & 0.982 & $\mathrm{R}$ & 0.845 & $\mathrm{R}$ & 0.947 \\
\hline $\mathrm{R}^{2}$ & 0.964 & $\mathrm{R}^{2}$ & 0.714 & $\mathrm{R}^{2}$ & 0.897 \\
\hline $\begin{array}{l}\mathrm{MBE} \\
\%\end{array}$ & -0.067 & $\begin{array}{l}\mathrm{MBE} \\
\%\end{array}$ & $-0,207$ & $\begin{array}{l}\text { MBE } \\
\%\end{array}$ & -0.392 \\
\hline $\begin{array}{l}\text { RMSE } \\
\%\end{array}$ & 25.05 & $\begin{array}{l}\text { RMSE } \\
\%\end{array}$ & 72.25 & $\begin{array}{l}\text { RMSE } \\
\%\end{array}$ & 40.34 \\
\hline
\end{tabular}

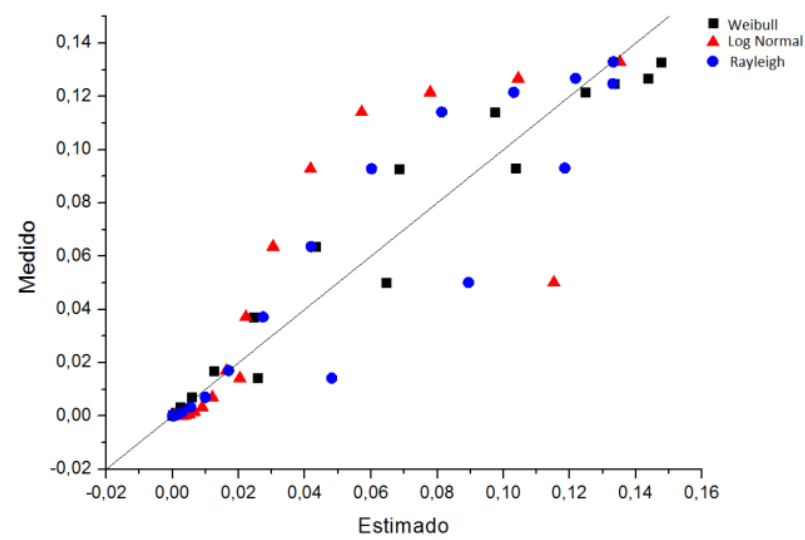

Fig.5.Dispersion plot between measured and estimated data provided by Weibull, Log Normal and Rayleigh distributions.

\section{Conclusions}

The study evaluated which of the statistical wind distributions best adapted to the data acquired from the beginning of 2005 to the end of 2009, by the anemometer at the height of 50 meters installed at SONDA site in the central area of the Southern region of Brazil.

In general, the distributions of Weibull, Log Normal and Rayleigh showed good correlations, all above $70 \%$. However, the Weibull distribution showed the best correlation and the smallest deviations from the observed values collected in the SONDA site. In summary, the Weibull distribution presents the best distribution for the central region of Rio Grande do Sul.

However, the data base analyzed must be expanded in order to minimize uncertainties discussed in the paper, and to make possible to get more reliable information about wind power in the central region of Rio Grande do Sul, in order to increase confidence to future investments in the energy generation in this region. 


\section{Acknowledgments}

The authors thank FINEP/MCT, the PIBIC/INPE - MCT Program for approving the research project and to LACESM/CT - UFSM for support. Thanks are due to Meteorological Instrumentation Laboratory (LIM/INPE) for the support in maintenance in SONDA sites.

\section{References}

Amêndola, C. A. M. Contribuição ao estudo de aerogeradores de velocidade e passo variáveis com gerador duplamente alimentado e sistema de controle difuso. Tese de Doutorado - Escola de Engenharia de São Carlos, Universidade de São Paulo, 2007. São Carlos, SP, Brasil.

Castro, R. M. G. Introdução À Energia Eólica, Energias Renováveis E Produção Descentralizada. Universidade Técnica De Lisboa, 2008. Portugal.

Chagas, R. C.; Martins, F. R.; Guarnieri, R. A.; Pereira, E. B.; Procedimento de validação de dados da rede de estações do Projeto SONDA. Anais do Congresso Brasileiro de Meteorologia, Florianópolis, 2006, SC, Brasil.

Grimm, A. M. Notas de Aula de Meteorologia Básica. Universidade Federal do Paraná, 1999. <http://fisica.ufpr.br/grimm/aposmeteo/index.html.>

Marques, J. Turbinas Eólicas: Modelo, Análise e Controle do Gerador de Indução com Dupla Alimentação. Dissertação de Mestrado, Universidade Federal de Santa Maria, 132p. 2004. Santa Maria,RS, Brasil.

Sansigolo, C. A. Distribuições De Probabilidade De Velocidade E Potência Do Vento, Revista Brasileira De Meteorologia, V.20, N.2, 207-214, 2005. 